\title{
Female Genital Mutilation - when do you call 101?
}

\author{
Kanch Seneviratne ${ }^{1}$, Katie Boog ${ }^{1}$, Susan Cooper ${ }^{1}$, Shereen Munatsi ${ }^{1}$, Elizabeth Carlin ${ }^{1,2}$ \\ ${ }^{1}$ Nottingham University Hospitals NHS Trust ${ }^{2}$ Sherwood Forest Hospitals NHS Foundation Trust
}

Background: Female genital mutilation (FGM) constitutes partial or total removal of the external female genitalia and is a human rights violation which is perpetuated by families due to cultural, traditional and religious reasons. The majority of FGM takes place in 28 African countries but some communities continue this practice on girls and women in the UK. Reporting cases of FGM in those aged under 18 years became mandatory in 2015. Protecting those who have been affected and safeguarding those at potential risk is paramount. ${ }^{1}$

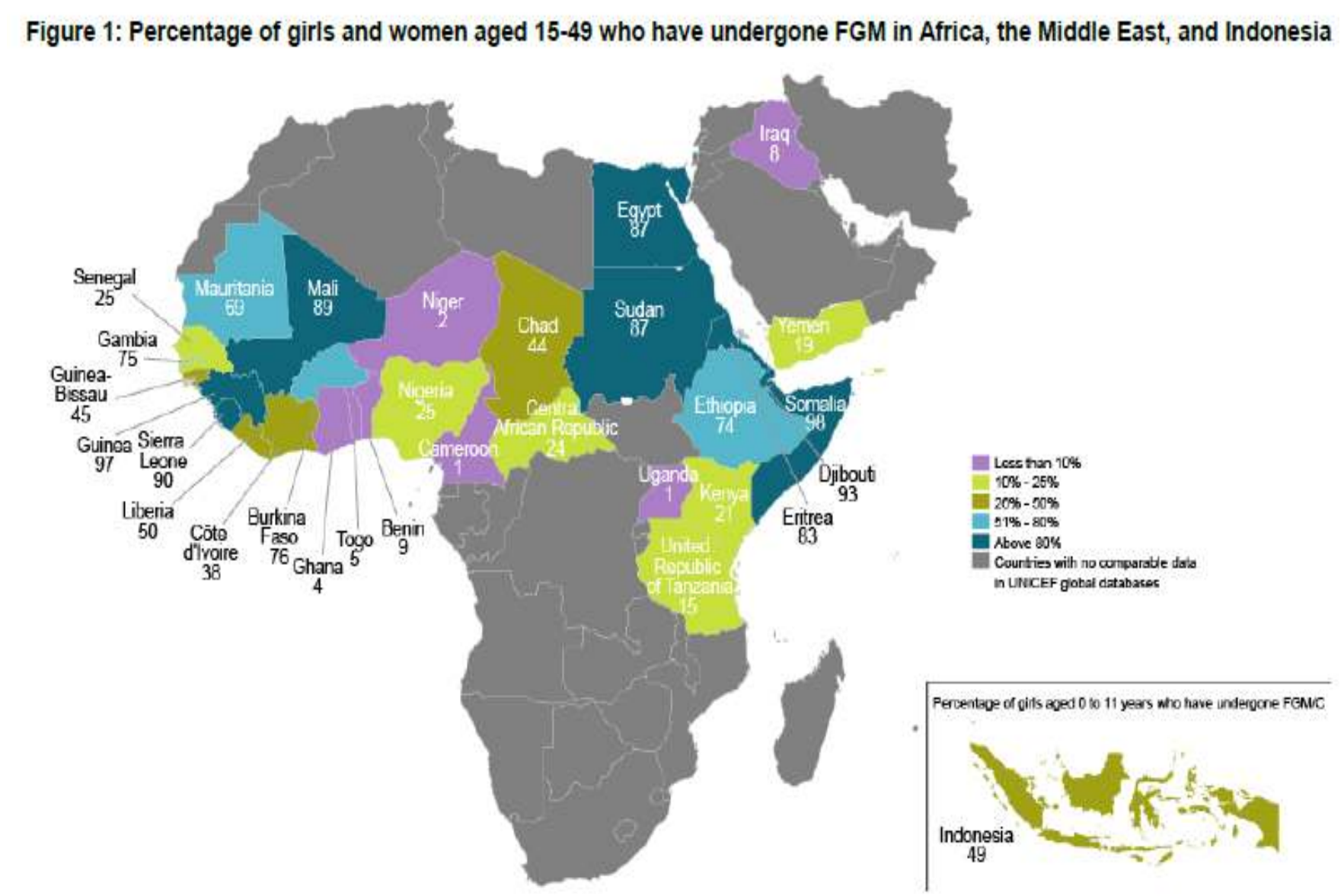

Aims:

- To evaluate staff knowledge about the management of an individual with FGM.

- To determine the volume of FGM seen in two neighbouring sexual health services in the East Midlands.

\section{Method:}

- Clinicians, including all doctors and Band 5-7 nurses with responsibility for examining patients, were recruited.

- They were asked to complete a questionnaire assessing their knowledge and understanding of the FGM care pathway.

- A diagnostic code for FGM had been introduced by the services in 2014. All case notes of women with this code were reviewed.

\section{Results - FGM data:}

- Twenty-two women, aged 24-59 years, had an FGM code.

- $91 \%$ were of Black African ethnicity.

- 1 in 5 had a documented attendance for a intrauterine device/system insertion.

- $13 \%$ had the grade of FGM documented.

- 1 genital piercing was coded as FGM.

- No onward referrals were made as no risks to female children were identified on assessment.

\section{Results - Clinician data:}

- Forty-six clinicians completed the questionnaire.

- $75 \%$ were aware of the need to ask about other daughters, social services referral and police contact.

- $70 \%$ were aware of the grades of FGM.

- 1 in 2 had already seen an individual with FGM, however 3 of these did not know the grades of FGM.

- $26 \%$ were unable to summarise appropriate action plans, of particular concern in this group were those who felt they understood the care pathway.

- 1 in 5 stated that they coded genital piercings as FGM.

\section{Table 1: Understanding of FGM care pathway}

\begin{tabular}{|l|l|l|}
$\begin{array}{l}\text { Do you understand the } \\
\text { care pathway for FGM? }\end{array}$ & Percentage & $\begin{array}{l}\text { Action taken if < 18yr } \\
\text { with FGM }\end{array}$ \\
\hline No & $13 \%$ & $\begin{array}{l}\text { Unable to provide } \\
\text { Appropriate action } \\
\text { described }\end{array}$ \\
\hline No & $22 \%$ & $\begin{array}{l}\text { Appropriate action } \\
\text { described }\end{array}$ \\
\hline Yes & $52 \%$ & $\begin{array}{l}\text { Limited understanding of } \\
\text { required action }\end{array}$ \\
\hline Yes & $13 \%$ & \\
\hline
\end{tabular}

Figure 2: Quick reference flow chart for FGM pathway

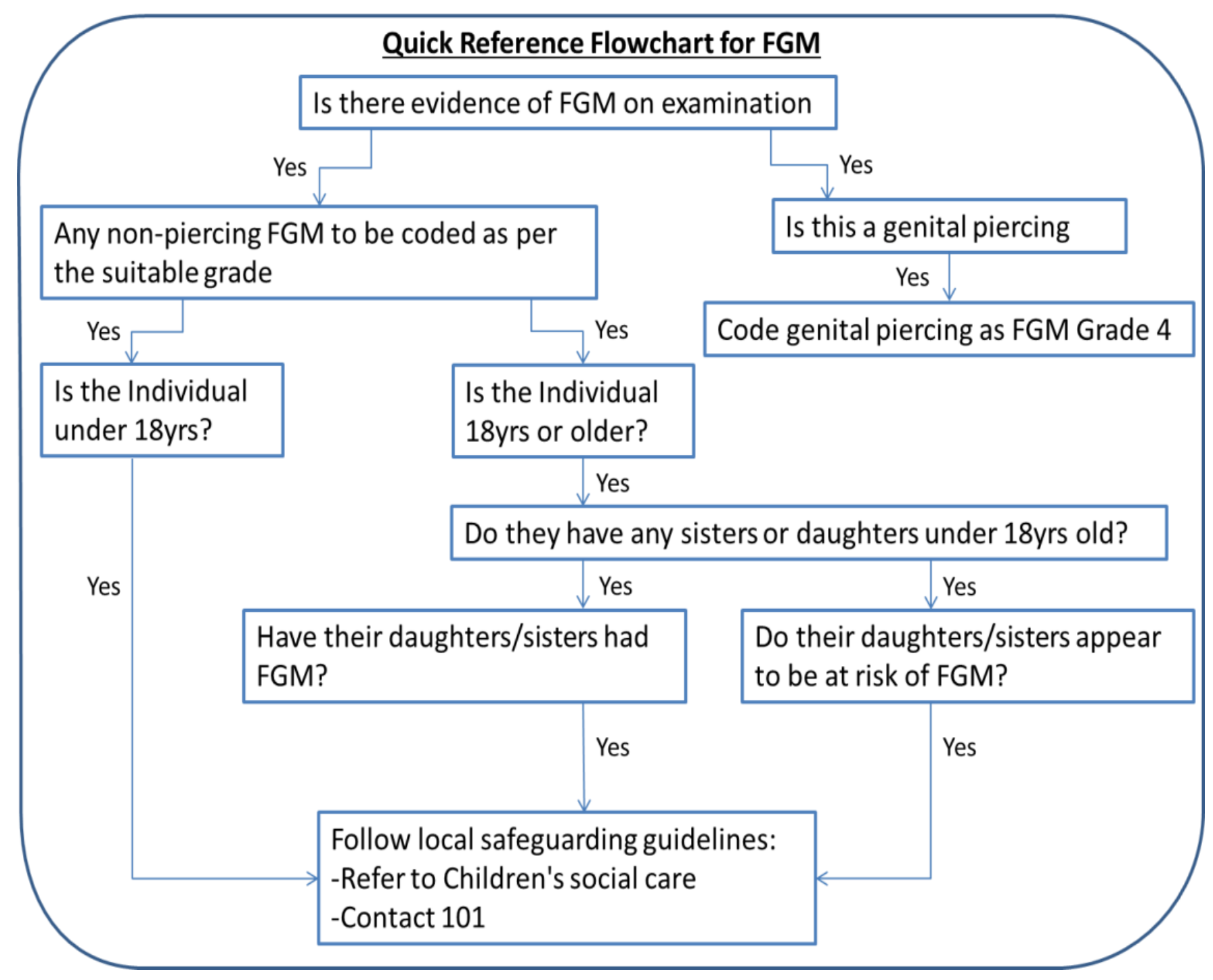

Conclusion: There is a clear knowledge gap in actions and coding required in relation to FGM. Over $80 \%$ of staff recognised this and requested training. Plans are underway to deliver this and close the gap as a priority. A flow chart for quick reference for the FGM pathway (Figure 2) has also been developed for in-clinic use. 